\section{XPS Investigation of X-Ray-Induced Reduction of Metal Ions}

\author{
ŞEFIK SÜZER \\ Bilkent University, Chemistry Department, 06533 \\ Ankara, Turkey
}

Index Headings: $\mathbf{X}$-ray-induced reduction of $\mathbf{A u}^{3+}, \mathbf{H g}^{2+}, \mathbf{B i}^{3+}, \mathrm{V}^{5+}$ and $\mathrm{W}^{6+}$; Electrochemical reduction potential; XPS.

\section{INTRODUCTION}

Structural information derived by using $\mathrm{X}$-rays is ever increasing and moving into all areas of pure and applied sciences, especially after wider utilization of synchrotron radiation facilities enabling easy access to the techniques such as X-ray absorption near-edge spectroscopy (XANES), extended X-ray absorption fine structure (EXAFS), and X-ray photoelectron spectroscopy (XPS) together with well-established analytical techniques such as X-ray fluorescence (XRF), X-ray diffraction (XRD), photon-induced X-ray emission (PIXE), total reflection X-ray fluorescence (TXRF), and synchrotron $X$-ray fluorescence (SXRF). Prolonged exposure of the samples to X-rays is common to all these techniques and is known to cause various kinds of radiation damage. ${ }^{1}$ A particular kind of damage is the reduction of the metal ions, which can cause severe interference in cases where determination of the formal oxidation state is important, as is the case in the majority of the applications of XANES, EXAFS, and XPS. ${ }^{2-10}$ Electron, ion, and other energetic particle exposure, which is frequently utilized for cleaning and/or depth-profiling, also causes damage, and similar to $\mathrm{X}$ rays, this approach invariably gives rise to the reduction of the metal ions to lower oxidation states and/or preferential removal of oxygen..$^{5,11-15}$ The extent of reduction, however, varies drastically from one metal ion to another.

In this contribution, we will demonstrate reduction by $\mathrm{X}$-rays of $\mathrm{Au}, \mathrm{Hg}, \mathrm{Bi}, \mathrm{V}$, and $\mathrm{W}$ metal ions during our XPS analysis of various kinds of samples we have carried out over the years. ${ }^{16,17}$ We will also discuss the possibility of correlating the ability of the metal ions to undergo Xray-induced reduction with their electrochemical reduction potentials.

\section{EXPERIMENTAL}

$\mathrm{Au}^{3+}, \mathrm{Hg}^{2+}$, and $\mathrm{Bi}^{3+}$ were deposited from their corresponding aqueous solutions onto gold metal or silicon wafers. An impregnating solution of $\mathrm{NH}_{4} \mathrm{VO}_{3}$ to zirconia powders was used for $\mathrm{V}^{5+}$, which was calcined for $2 \mathrm{~h}$ at $723 \mathrm{~K} .{ }^{18}$ A glass sample coated (via magnetron sputtering) with a thin layer $(\sim 100 \mathrm{~nm})$ of $\mathrm{WO}_{3}$ was used for $\mathrm{W}^{6+}$. Similar experiments were also carried out with different salts and/or substrates, resulting in similar observations. A Kratos ES300 electron spectrometer with unmonochromatized $\mathrm{MgK} \alpha \mathrm{X}$-rays $(1253.6 \mathrm{eV})$ was used for XPS analysis as well as X-ray exposure in vacuum.

Received 6 May 2000; accepted 28 July 2000.
The power of the anode was kept at a minimum level (15 $\mathrm{kV}, 8 \mathrm{~mA}$ ) to avoid severe radiation damage. The X-rays were unfocused and consisted mainly of $\mathrm{Mg}(\mathrm{K} \alpha$ and $\beta)$ lines as well as the Bremstrahlung (up to $15 \mathrm{kV}$ and at a maximum of about $5 \mathrm{kV}$ ), and they hit an approximately $1 \mathrm{~cm}^{2}(7 \mathrm{~mm} \times 15 \mathrm{~mm})$ area of the sample. Hence the power density can be estimated to be about $120 \mathrm{~W} /$ $\mathrm{cm}^{2}$.

\section{RESULTS AND DISCUSSION}

The penetration depth of the X-rays $(>1000 \mathrm{~nm})$ is much larger than the sampling depth of XPS, which is less than $10 \mathrm{~nm}$ for common materials, ${ }^{16}$ so we can safely assume that the X-ray damage is uniform for the samples we investigated by XPS. Secondly, the damage caused is more or less linearly dependent on the dose; hence nonlinear effects can be ruled out. Furthermore, in order to ensure that the spectral changes we observed were the result of the X-ray bombardment, we separately controlled the stability of all the metal ions investigated under UHV conditions (up to 4 days).

$\mathbf{A u}^{3+}$ on Silicon. Figure 1 displays part of the XPS spectrum of an aqueous solution of $\mathrm{HAuCl}_{4}$ deposited on a silicon wafer after drying in air and pumping in the vacuum chamber of the spectrometer for more than $4 \mathrm{~h}$. The Si $2 p$ peak shows a doublet structure due to the native surface oxide $\left(\mathrm{SiO}_{x}\right)$, the thickness of which can be estimated to be less than $3 \mathrm{~nm}$ by considering the angular dependence of the $\mathrm{Si}^{4+}$ and $\mathrm{Si}^{0}$ peaks. ${ }^{16}$ As shown at the bottom of the figure, the $\mathrm{Au} 4 \mathrm{f}$ peaks can be fitted to two spin-orbit doublets $\left(4 \mathrm{f}_{7 / 2}\right.$ and $\left.4 \mathrm{f}_{5 / 2}\right)$ corresponding to $\mathrm{Au}^{3+}$ and $\mathrm{Au}^{0}{ }^{16,17}$ During the course of irradiation by $\mathrm{X}$-rays, the relative intensity of the $\mathrm{Au}^{3+}$ peak decreases and that of the $\mathrm{Au}^{0}$ peak increases, and almost a complete reduction occurs after $10 \mathrm{~h}$. It is also noteworthy to mention

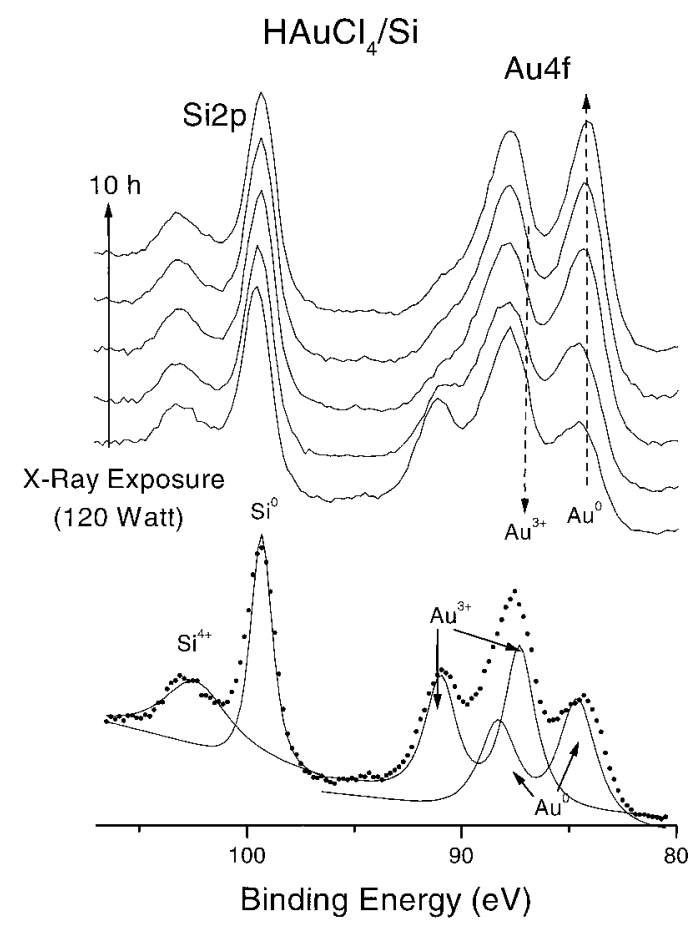

FIG. 1. Part of the XPS spectra of $\mathrm{HAuCl}_{4}(\mathrm{aq})$ deposited on a silicon substrate as a function of the X-ray dose. 


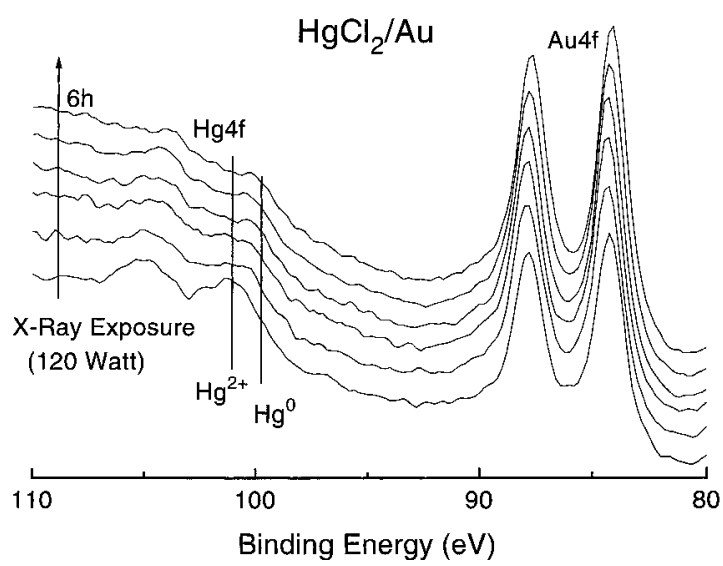

FIG. 2. Part of the XPS spectra of $\mathrm{HgCl}_{2}$ (aq) deposited on a gold substrate as a function of the $\mathrm{X}$-ray dose.

that, even at the very beginning of the X-ray bombardment, more than $30 \%$ of the gold was already reduced to $\mathrm{Au}^{0}$. The $\mathrm{Cl} / \mathrm{Au}$ stoichiometry (as determined by using the $\mathrm{Cl} 2 \mathrm{p}$ and $\mathrm{Au} 4 \mathrm{f}$ peaks) was 2.8 at the beginning and came down to 1.2 after $10 \mathrm{~h}$.

$\mathbf{H g}^{2+}$ on Gold. Figure 2 shows a behavior similar to that of $\mathrm{Au}^{3+}$ on silicon. $\mathrm{Hg}^{2+}$ deposited on a gold substrate from aqueous $\mathrm{HgCl}_{2}$ underwent partial reduction to $\mathrm{Hg}^{0}$ within $6 \mathrm{~h}$. Gold was chosen as the substrate rather than silicon since both the $\mathrm{Si} 2 \mathrm{p}$ and $\mathrm{Hg}$ 4f levels coincidentally have binding energies around $100 \mathrm{eV}$. A second problem in $\mathrm{Hg}$ is the disappearance of the signal [as can also be inferred from the spectra both from the decrease of the $\mathrm{Hg}$ signal and from the corresponding increase of the substrate (Au) signal] due to the relatively high vapor pressure of mercury. Nevertheless, partial reduction of $\mathrm{Hg}^{2+}$ to $\mathrm{Hg}^{0}$ occurs by $\mathrm{X}$-ray exposure, but no $\mathrm{Hg}^{0}$ was present at the outset of the experiment.

$\mathrm{Bi}^{3+}$ on Gold. Figure 3 shows similar spectra for $\mathrm{Bi}^{3+}$ being partially reduced to $\mathrm{Bi}^{0}$ during $10 \mathrm{~h}$ of exposure to $\mathrm{X}$-rays. Here again, no $\mathrm{Bi}^{0}$ signal was present at the outset of the exposure.

$\mathbf{V}^{5+}$ on Zirconia. Catalytic activity of the various oxidation states of vanadium is important in industrial ap-

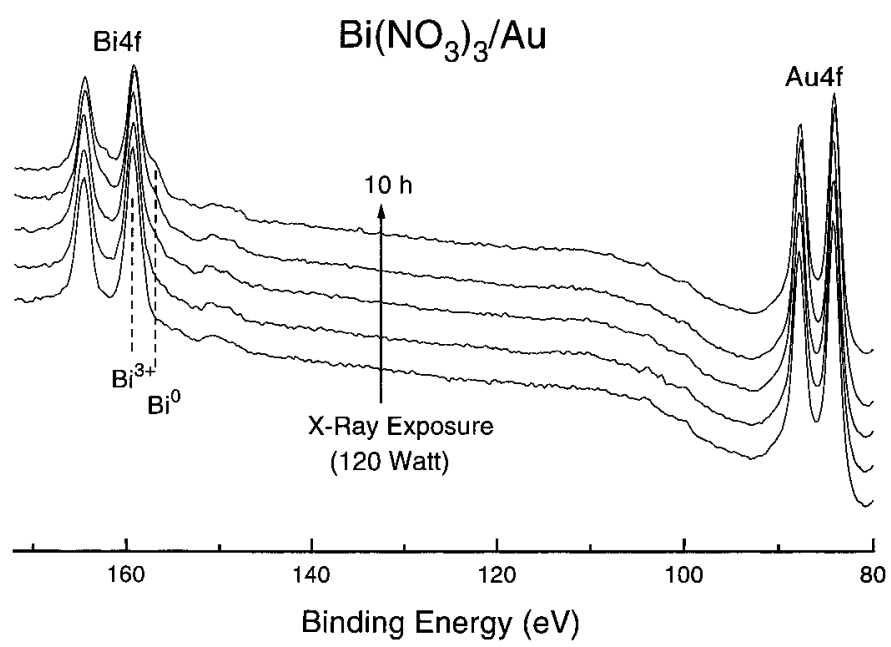

FIG. 3. Part of the XPS spectra of $\mathrm{Bi}\left(\mathrm{NO}_{3}\right)_{3}$ (aq) deposited on a gold substrate as a function of the X-ray dose.

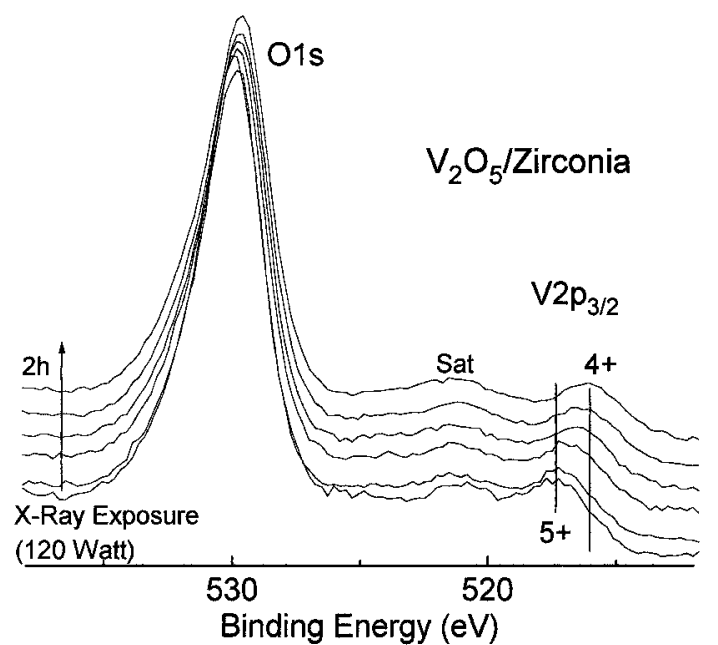

FIG. 4. Part of the XPS spectra of $\mathrm{V}_{2} \mathrm{O}_{5}$ (aq) deposited on zirconia as a function of the X-ray dose.

plications. During our investigation of $\mathrm{V}_{2} \mathrm{O}_{5}$ on zirconia, we observed rapid reduction of the $\mathrm{V}^{5+}$ to $\mathrm{V}^{4+}$, as is also shown in Fig. $4 .{ }^{18}$ Two hours of $\mathrm{X}$-ray exposure causes almost complete reduction of $\mathrm{V}^{5+}$ to $\mathrm{V}^{4+}$.

$\mathrm{W}^{6+}$ Thin Coatings. Thin coatings of tungsten in various oxidation states give different colors and are also the basis for various applications of electrochromic materials. ${ }^{19}$ Here also $\mathrm{W}^{6+}$ is partially reduced by $\mathrm{X}$-rays to $\mathrm{W}^{5+}$, as shown in Fig. 5 .

Thermodynamic Considerations. Various attempts to correlate the mechanism(s) of this energetic particle (electrons, ions, and X-rays) reduction to the kinematics of the surface bombardment or to some thermodynamic properties of the metals and/or ions (such as melting or boiling points of the metals or heat of formation of the corresponding oxides) have not been very successful. ${ }^{4-14}$ In our recent analysis of the chemical state of the analyte species collected on a water-cooled silica tube during atom-trapping atomic absorption spectrometric determination, we have established that gold was deposited as $\mathrm{Au}^{0}$, manganese as $\mathrm{Mn}^{2+}$, and bismuth as both $\mathrm{Bi}^{3+}$ and

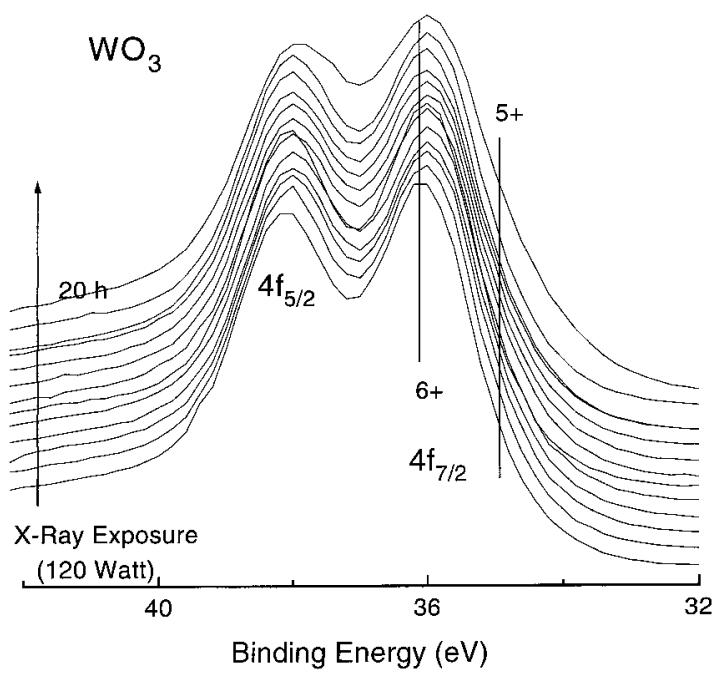

FIG. 5. Part of the XPS spectra of a thin film of $\mathrm{WO}_{3}(\mathrm{aq})$ deposited on a glass substrate as a function of the X-ray dose. 
TABLE I. Melting points, heats of fusion, free energy of formation of the oxides, and reduction potentials of the metal ions studied. ${ }^{21}$

\begin{tabular}{lccccc}
\hline & $\begin{array}{c}\text { Time for } \\
\text { reduction by } \\
120 \mathrm{~W}(\mathrm{~h}) \\
\mathrm{X})\end{array}$ & $\begin{array}{c}\mathrm{M} . \mathrm{P} .(\mathrm{m}) \\
(\mathrm{K})\end{array}$ & $\begin{array}{c}\Delta H_{\text {fus }}(\mathrm{m}) \\
(\mathrm{kJ} / \mathrm{mol})\end{array}$ & $\begin{array}{c}\Delta G_{\text {for }} \text { of } \\
\text { the oxide } \\
(\mathrm{kJ} / \mathrm{mol})\end{array}$ & $\begin{array}{c}\epsilon_{\text {red }}^{0} \text { in aq. } \\
\text { soln. (V) }\end{array}$ \\
\hline $\mathrm{Au}^{3+}$ & $12^{\mathrm{a}}$ & 1337 & 12.6 & +163 & +1.50 \\
$\mathrm{Hg}^{2+}$ & 20 & 234 & 2.3 & -58.5 & +0.90 \\
$\mathrm{Bi}^{3+}$ & 40 & 544 & 11.3 & -494 & +0.31 \\
$\mathrm{~V}^{5+}$ & 2 & 2183 & 21.5 & -1420 & $+0.96^{\mathrm{b}}$ \\
$\mathrm{W}^{6+}$ & 80 & 3695 & 52.3 & -760 & $+0.04^{\mathrm{c}}$ \\
\hline
\end{tabular}

${ }^{a}$ These values are approximate and are meaningful only relative to each other.

${ }^{\mathrm{b}}$ Reduction potential of $\mathrm{V}^{5+}$ to $\mathrm{V}^{4+}$.

${ }^{\mathrm{c}}$ Reduction potential of $\mathrm{W}^{6+}$ to $\mathrm{W}^{5+}$.

$\mathrm{Bi}^{0}{ }^{20}$ Furthermore, we have postulated that the electrochemical potential is the determining factor for the stability of the chemical state of the metal ion. Extending this approach to the $\mathrm{X}$-ray-induced reduction, we can also see a similar correlation (Table I). $\mathrm{Au}^{3+}$ with a very high and positive reduction potential of $+1.50 \mathrm{~V}$ readily undergoes reduction, while the reduction of $\mathrm{Hg}^{2+}$ is only partial (reduction potential of $\mathrm{Hg}^{2+}$ is $+0.90 \mathrm{~V}$ ) and that of $\mathrm{Bi}^{3+}$ takes longer (reduction potential of $\mathrm{Bi}^{3+}$ is +0.30 V). Although we have not observed complete reduction to their metallic states for $\mathrm{V}^{5+}$ and $\mathrm{W}^{6+}$, their reduction potentials to their intermediate states are also positive (Table I). Also note that the smaller the reduction potential, the longer it takes for the reduction.

Naturally, during the metal ion reduction an accompanying oxidation must also take place. In the case of $\mathrm{Au}$, we determined this accompanying oxidation as partly $\mathrm{Cl}^{-}$to $\mathrm{Cl}_{2}$ (since the $\mathrm{Cl} / \mathrm{Au}$ ratio was reduced to 1.2 from 2.8), but there must be other species as well, and we suspect they are the oxide or the hydroxide ions. Our suspicion is based on our observations as well as those of others that severe oxygen-deficient stoichiometry results during noble gas ion bombardment of metal oxides containing similar metal ions. ${ }^{5,11-15}$
It is interesting that the electrochemical reduction potentials determined in aqueous solutions can also be the determining factors for the stability of the ions on various surfaces and/or towards energetic particle bombardment. To this end one must also consider that, during energetic particle bombardment, copious amounts of secondary low-energy electrons are produced, which must be inducing reactions similar to the ones in the aqueous phase.

1. Point Defects in Solids, Vol. 1, General and Ionic Crystals, J. H. Crawford and L. M. Slifkin, Eds. (Plenum Press, New York, 1972).

2. J. S. Brinen and L. A. Wilson, J. Chem. Phys. 56, 6256 (1972).

3. B. Wallbank, C. E. Johnson, and I. G. Main, J. Electron Spectrosc. Relat. Phen. 4, 263 (1974).

4. R. G. Copperthwaite, Surf. Interface Anal. 2, 17 (1980).

5. S. Storp, Spectrochim. Acta 40B, 745 (1985).

6. S. Aduru, S. Contarini, and J. W. Rabalais, J. Phys. Chem. 90, 1683 (1986).

7. G. P. Halada, C. R. Clayton, and D. H. Lindsley, Mat. Sci. Eng. A103, L5 (1988).

8. N. M. D. Brown, J. A. Hewitt, and B. J. Meenan, Surf. Interface Anal. 18, 187 (1992).

9. A. Fernandez, J. P. Espinos, D. Leinen, A. R. Gonzalez-Elipe, and J. M. Sanz, Surf. Interface Anal. 22, 111 (1994).

10. F. Vreugdenhil, B. Hagenhoff, and P. C. Zalm, Surf. Interface Anal. 25, 46 (1997).

11. R. Kelly, Surf. Sci. 100, 85 (1980).

12. G. Betz and G. K. Werner, in Topics in Applied Physics, Vol. 52, R. Behrisch, Ed. (Springer-Verlag, Berlin, 1983), p. 11.

13. J. B. Malherbe, S. Hofmann, and J. M. Sanz, App. Surf. Sci. 27, 355 (1986)

14. D. F. Mitchell, G. I. Sproule, and M. J. Graham, Surf. Interface Anal. 15, 487 (1990).

15. S. Süzer, F. Kadirgan, and H. M. Sohmen, Sol. Energy Mat. Sol. Cells 56, 183 (1999).

16. D. Briggs and M. P. Seah, Practical Surface Analysis, Vol. 1, Auger and X-ray Photoelectron Spectroscopy (Wiley, Chichester, 1996).

17. S. Süzer, N. Ertas, S. Kumser, and O. Y. Ataman, Appl. Spectrosc. 51, 1537 (1997)

18. M. Kantcheva, Phys. Chem. Chem. Phys. 2, 3043 (2000).

19. B. Tell, J. Electrochem. Soc. 127, 2451 (1979).

20. S. Süzer, N. Ertas, and O. Y. Ataman, Appl. Spectrosc. 53, 479 (1999).

21. Handbook of Physics and Chemistry (CRC Press, Boca Raton, Florida, 1995), 75th ed. 